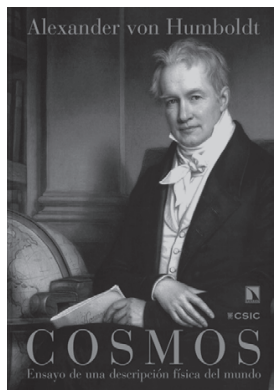

\title{
Alexander von Humboldt. Cosmos. Ensayo de una descripción física del mundo
}

\author{
Santiago de Chile / Madrid: Los libros de la Catarata / Consejo \\ superior de Investigaciones Científicas, España / Centro de \\ Investigaciones Diego Barros Arana, Dirección de Bibliotecas, \\ Archivos y Museos, 2011, 959 p.
}

\author{
Alex Paulsen E. ${ }^{1}$
}

A través de los constantes intercambios académicos entre España y $\mathrm{Chile}^{2}$, se logra conformar esta magna edición del Cosmos. Ensayo de una descripción física del mundo, incluyendo la primera traducción del quinto tomo al español que se hace desde su aparición en este idioma en 1874. Entre sus primeras páginas se encuentran prólogos realizados por Rafael Sagredo Baeza (Pontificia Universidad Católica de Chile), Miguel Ángel Puig-Samper (Consejo Superior de Investigaciones Científicas), el estudio introductorio de Sandra Rebok (Consejo Superior de Investigaciones Científicas) y en sus páginas finales un epílogo de Ottomar Ette (Universidad de Postdam).

Alexander von Humboldt (1769-1859) es quizás uno de los intelectuales más influyentes en el ámbito del quehacer geográfico, así como también en otras ciencias. Sin embargo, su nombre se le asocia a una corriente que recorre nuestras costas desde el círculo polar antártico hasta el litoral peruano en dirección hacia las zonas ecuatoriales, sin mayor reconocimiento que ese. La edición que se presenta a continuación es un aporte a la memoria, que viene a suplir de alguna forma este desconocimiento del público en general chileno.

\footnotetext{
1 Magíster (C) en Geografía y Geomática, Instituto de Geografía, Pontificia Universidad Católica de Chile (Chile).E-mail: appaulse@uc.cl

2 Específicamente entre la Editorial Los libros de la Catarata (España), el Consejo Superior de Investigaciones Científicas (CSIC, España) y la Dirección de Bibliotecas, Archivos y Museos (Chile), el Centro de Investigaciones Diego Barros Arana (Chile) y la Pontificia Universidad Católica de Chile.
}

Proveniente de la ciudad de Tegel, cerca de Berlín, este famoso viajero y científico prusiano, se formará en el seno de una familia aristócrata, en donde su padre era chambelán del rey de Prusia y su madre una acaudalada mujer, la cual influiría de forma decisiva en la personalidad de Alexander. Durante su juventud fue educado por Joachim Heinrich Campe y $^{3}$ Gottlob C. Kunth, en donde el primero despertará la imaginación a través de las narrativas de viajes, mientras que el segundo formará a Alexander en la filosofía rusoniana y la adquisición de nuevos idiomas.

Posteriormente, su formación universitaria estará ligada a las Universidades de Gotinga y Frankfurt, en donde se graduará en física y geología respectivamente, además de llevar a cabo estudios de astronomía, botánica y meteorología. Con ello, ya se percibe el interés por parte de Humboldt de adquirir conocimientos de diversas ciencias, lo cual sería determinante en la concepción del Cosmos. Luego, realizaría estudios en la Academia de Minería de Freiberg, en Sajonia, siendo contratado por el barón de Heinitz para desarrollar estudios mineralógicos y de historia natural en Holanda, Inglaterra y Francia. En este contexto, publica Flora Fribergensis en 1793, en donde establece que la geografía de las plantas, la geografía de las rocas y la geografía de los animales deberían formar un área de estudio denominada Geognosia en latín y Erdkunde en alemán (Unwin, 1995).

\footnotetext{
3 Autor del libro Robinson Crusoe en conjunto con Daniel Defoe.
} 
En este momento, las grandes expediciones que se llevan a cabo son un aliciente para el desarrollo de las investigaciones de Alexander von Humboldt, figurando entre ellas las realizadas por Louis Antoine de Bougainville (1766-1769), James Bruce (1768-1773), Carsten Niebuhr (1761-1767), Alejandro Malaspina (1789-1794) y los viajes de James Cook (1768, 1771, 1772, 1775 y 1776-1780) (Rebok, 2011). A pesar de esto, desde muy joven se había planteado la idea de llevar a cabo un viaje de carácter científico sin saber claramente el destino, ya que la expedición en sí representaba un desafío personal. Con una formación académica diversa y con los medios (sobre todo políticos) para llevar a cabo expediciones de ultramar, Humboldt se aventurará a conformar embarcaciones que lo transporten a las regiones tropicales.

En primera instancia, dos proyectos de viaje fueron cancelados por motivos económicos y políticos. Luego de ello, Alexander viaja a España para recibir el apoyo de S.M. Católica, en donde reside desde enero a junio de 1799 con el objetivo de establecer diversas relaciones científicas, políticas y diplomáticas que faciliten la preparación y aprobación las expediciones americanas. Finalmente en junio de 1799, Humboldt en conjunto con Aimé Bonpland, parten desde La Coruña en la corbeta española Pizarro rumbo a las Islas Canarias. Su periplo estará marcado por lugares como el puerto de Cumaná y la costa de Paria, Nueva Andalucía, Nueva Barcelona, de Venezuela y de la Guyana española, así como también La Habana, las planicies del Calabozo, de los ríos Apure y Orinoco, Cartagena de Indias (Colombia) Santa Fe de Bogotá, Quito, Lima, Guayaquil, México, Filadelfia, finalizando dicha expedición en 1804 (Rebok, 2011).

Resultado de ello, se generaron observaciones mineralógicas, astronómicas, químicas, morales y una colección de 6.000 especies diferentes de plantas. Con ello publicará el Ensayo político sobre el Reino de la Nueva España, el Viaje a las regiones equinocciales del Nuevo Continente, Cuadros de la Naturaleza y Ensayo sobre la geografía de las plantas, además de diversos artículos que serán publicados en diferentes revistas. Esta creciente producción científica delinea- rá el genio, la capacidad de observación y el método aplicado por el prusiano. En este sentido, estos ensayos muestran ideas sobre la ecología, la evolución y el ecúmene, que serán pioneras en ciencias tan diversas como la botánica y la geografía de la plantas (Buttimer, 2003), además de establecer nuevos paradigmas en las ciencias del ambiente global las cuales se consolidarán luego de dos siglos (Ezcurra, 2002). Según Sachs (2003), de esta expedición resultaron treinta volúmenes, dentro de los cuales también se hacía una severa crítica al sistema colonialista que se había implantado desde el centro hacia la periferia, considerando la esclavitud y las formas de extracción de los recursos, y debido a esto último estableciendo supuestos que hacen alusión a la ecología y la justicia ambiental (Sachs, 2003; Zeuske, 2008).

La geografía física y la geografía humana estaban implícitas en los análisis realizados por Humboldt, por lo que su intención de unificar los saberes era parte de sus concepciones epistemológicas y metodológicas. Con esta idea totalizadora del saber, sus métodos y formas de sintetizar los datos recogidos durante sus expediciones, tenían como objetivo establecer una visión holística de los fenómenos que se generaban en la interrelación entre los aspectos naturales y humanos. El despliegue de una cantidad considerable de instrumentos de medición no tan solo destaca el genio investigativo sino que también su nueva forma de hacer ciencia. En este sentido la idea de progreso siempre estuvo presente en Humboldt, ya que este estaba convencido de que los avances científicos debían ir en ayuda de la humanidad.

Estas posturas no solo obedecen a la formación y desarrollo académico de Alexander, sino que también a un contexto marcado por la transición entre la llustración y el Romanticismo alemán. El pensamiento filosófico que se desarrolla en la Europa del siglo XIX, está marcada por el auge del idealismo de Hegel, la economía política de Marx y el positivismo de Comte. La postura que tuvo el prusiano frente a estas corrientes filosóficas estuvo dada por la consideración de algunos postulados, como los principios de la investigación empírica, el progreso histórico de la sociedad y el liberalismo radical. Sin embargo, se alejó de las formulaciones positivistas de Comte, 
de la filosofía idealista de Hegel y el programa revolucionario de Marx y Engels (Unwin, 1995).

Con todo este desarrollo científico y expedicionario, Humboldt concretará una de las obras más ambiciosas de su vida: El "Cosmos". El origen de la idea se remonta a las diversas conferencias que comenzó a dictar entre 1825 y 1828 en París y Berlín. Durante su estancia en París dictó charlas sobre la descripción física del mundo, en donde trataba de verificar si sus interrelaciones eran coherentes dentro de su teoría. Luego en Berlín expone sus ideas y concepciones sobre geografía física, teniendo tal éxito que deberá volver a repetirlas en la Singakademie de la misma ciudad. Debido al éxito de las conferencias y la asistencia de una cantidad considerable de público general a estas, no tardaron en aparecer las propuestas editoriales. Finalmente en 1828 se firma un contrato con Johann Friedrich Cotta en donde se acuerda publicar no tan solo el Cosmos, sino que también el conjunto de conferencias que dicto Humboldt en París y Berlín (Rebok, 2011).

A pesar de estar en condiciones de comenzar a elaborar el escrito del Cosmos, esto no se realizó sino que hasta diecisiete años después, debido a un viaje a Asia y la edición de Examen critique (1836-1839). En 1845 verá la luz el primer tomo y en 1862 se edita finalmente el quinto volumen de manera póstuma. El primero de ellos versará sobre la bóveda celeste principalmente de las estrellas, planetas, la luna, la tierra y sus características físicas a nivel general (aspectos inorgánicos) y finalmente la vida orgánica considerando la flora y fauna. En el segundo volumen, los temas giran en torno a la percepción histórica que ha tenido el hombre de la naturaleza desde los griegos hasta el siglo XIX, así como también la contemplación que hacían de ellas las diversas culturas europeas. El tercer tomo trata sobre el sistema solar y aspectos de la astronomía sideral o como señalaría Humboldt a la uranología. El cuarto libro de esta colección estará enfocado en una descripción de los fenómenos terrestres como la intensidad magnética de la tierra y su actividad interior, y cómo se manifiesta esta en la superficie del planeta. También se desarrollan descripciones y análisis sobre los volcanes, su actividad, formas y efectos. Finalmente el volumen póstumo de esta gran obra, concluye describiendo los resultados de las observaciones en el área de los fenómenos telúricos y su relación con las actividades volcánicas, referidas a los efectos destructivos, constructivos y transformadores de esta.

La edición que se reseña a continuación logra mostrar en toda su magnitud la gran empresa llevada a cabo por este intelectual durante parte importante de su vida. Esta no tan solo viene a dejar una nueva edición de los tomos que se editaron durante el siglo XIX, sino que también es la primera edición en castellano que incluye la traducción al español del quinto tomo original entregado por Humboldt a la editorial justo antes de faIlecer. Su traducción se realizó con un mayor rigor científico y a pesar de sus extensos pies de páginas, queda en evidencia la erudición de Alexander von Humboldt.

La vigencia de este intelectual debe quedar en evidencia con esta edición del Cosmos, y no tan solo ser recordado como la corriente marina que circula por nuestras costas. Es menester señalar que su influencia marcó a varios intelectuales del siglo XIX chileno, desde Benjamín Vicuña Mackenna, pasando por Andrés Bello (con quien conversó en Venezuela) (Ramírez, 2004), Claudio Gay e Ignacio Domeyko entre otros. La lectura de esta edición dejará en claro los diversos aportes a las ciencias que generó Humboldt, los cuales fueron decisivos en la conformación de la geografía moderna en conjunto con Ritter, así como también en la constitución de nuevos paradigmas científicos que fueron desarrollados durante el siglo XX.

\section{Referencias bibliográficas}

BUTTIMER, A. Renaissance and re-membering geography: pioneering ideas of Alexander von Humboldt 1769 - 1859. South African Geographical Journal, 2003, p. 125-133.

EZCURRA, E. Redescubriendo a Alexander von Humboldt. Ciencias, 2002, p. 4-11.

HARTSHORNE, R. The concept of geography as a science of space, from Kant and 
Humboldt to Hettner. Annals of the Association of American Geographers, 1958, p. 97108.

RAMÍREZ, A. Influencias en los artículos de Bello. In: ERICKSON, R.; FONT, M. \& SCHWARTZ, B. Alexander von Humboldt From the Americas to the Cosmos. New York: The Graduate Center, CUNY, 2004, p. 353-360.

REBOK, S. Introducción . En: Von Humboldt, A. Cosmos Ensayo de una descripción física del mundo. Madrid: Los Libros de la Catarata, 2011, p. XV - XXXVII.
SACHS, A. The ultimate "other": post-colonialism and Alexander von Humboldt's ecological relationship with nature. History and Theory, 2003, p. 111-135.

UNWIN, T. El lugar de la geografía. Madrid: Cátedra, 1995.

ZEUSKE, M. Humboldt, esclavitud, autonomismo y emancipación en las Américas, 1791-1825. En: CUESTA, M. \& REBOK, S. Alexander von Humboldt Estancia en España y viaje americano. Madrid: Consejo Superior de Investigaciones Científicas, 2008, p. 257-277 